\title{
NEOVASCULARIZATION OF THE DISC IN CHRONIC SIMPLE GLAUCOMA*†
}

\author{
BY \\ M. SENGUPTA \\ From the Department of Ophthalmology, Eye Infirmary, Medical College, Calcutta. \\ (Professor-in-Charge: Dr. K. Sen)
}

New blood vessels appear on the disc in many ocular conditions, but their appearance in glaucoma is infrequent. Duke-Elder (1940) describes the formation of new blood vessels on the retina and the optic disc due to glaucoma as common, and cites several references from the older literature (Von Graefe, 1854; Hormuth, 1903; Bloch, 1906; Axenfeld, 1911; Kraupa, 1915). Fuchs (1951) also mentions the occurrence of newly formed bloodvessels on or close to the optic disc in glaucomatous eyes. But no reference of the condition in chronic simple glaucoma is found in any recent literature.

In India neovascularization of the retina or disc has been known to occur in epidemic dropsy glaucoma where the fundus often shows retinal haemorrhage. In the Eye Infirmary, Medical College, Calcutta, where large numbers of glaucoma cases are seen yearly, new vessel formations are seldom encountered in conditions other than vascular glaucoma.

\section{Case Reports}

Case 1, a married woman aged 58, came to the Eye Infirmary, Medical College, Calcutta, on June 15,1951 , with the complaint of hazy vision in the left eye. She also gave the history of occasionally seeing rainbow haloes around lights in the left eye.

Examination.-Left eye: Visual acuity 6/60, cornea steamy, anterior chamber shallow, disc shallow cupping, tension $40 \mathrm{~mm}$. $\mathrm{Hg}$ (Schiötz), visual field marked nasal depression.

Right eye: Visual acuity $6 / 9$, cornea clear, anterior chamber shallow, disc slight physiological cupping, tension $28 \mathrm{~mm}$. $\mathrm{Hg}$ (Schiötz), visual field normal.

Therapy.-She was given pilocarpine 1 per cent. drops, but as the tension did not improve, a left trephine was performed on June 28, 1951.

The patient remained well until March, 1952, when she complained of hazy vision in the right eye.

Examination (March 31, 1952).-Tension $30 \mathrm{~mm}$. Hg (Schiötz) in the right eye and $25 \mathrm{~mm}$. Hg (Schiötz) in the left eye.

Therapy.-Pilocarpine 1 per cent. drops were advised for the right eye. One week later she complained of sudden deterioration of vision in the right eye.

Examination.-Visual acuity 6/24, cornea clear, anterior chamber shallow, fundus full of scattered superficial flame-shaped haemorrhages. Blood and urine examination showed nothing abnormal. Wassermann reaction negative. Blood pressure 145/80.

With the usual treatment with Rutin, vitamin $\mathrm{C}$, and iodide, the haemorrhages completely disappeared leaving no trace in 6 months' time.

+ Received for publication May 8, 1954.

Read before the meeting of the Ophthalmological Society of Bengal, January 21, 1954. 
Further Developments. - In January, 1953, the patient was seen by Prof. Karl Lindner who found the ocular tension in both the eyes to be within normal limits. His report on the fundus condition was "slight physiological cupping of the disc in the right eye and cupping of the disc with optic atrophy in the left eye ". In May, 1953, the patient came again with the complaint of hazy vision in the morning. The right fundus showed slight physiological cupping of the disc, but on the nasal half there was an anastomotic venous loop. There was no other new vessel formation in any other part of the fundus, and no sign remained of the previous retinal haemorrhages. The left fundus showed besides the cupping of the disc with optic atrophy a very well-marked anastomotic vein on the temporal half (Fig. 1). Had not this patient been under constant observation since the beginning of the illness, the new vessel formations would have been diagnosed as possibly of congenital origin. In October, 1953, the patient had a heart attack, and the eyes were examined a fortnight later. The left fundus condition was as before, but in the right eye was a large patch of haemorrhages with exudates along the inferior temporal vein. The new blood vessels seen on the discs of both eyes showed no further change. When the patient was last examined (January 18,1954$)$ the haemorrhages and exudates in the right eye had been partially absorbed.

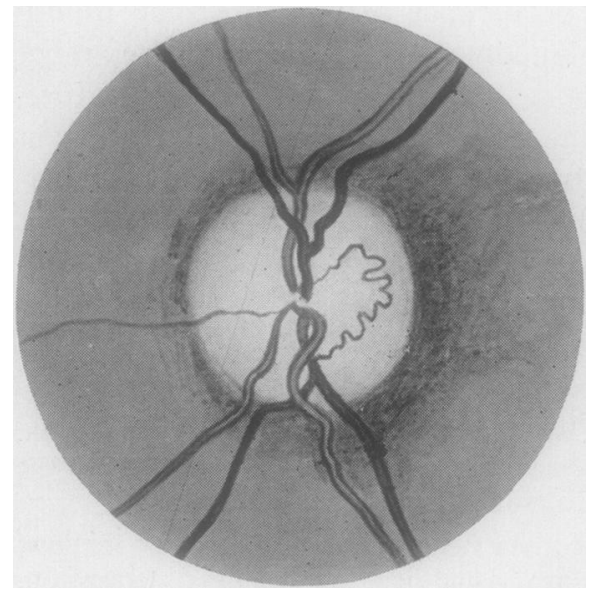

FIG. 1.-Case 1, left eye, showing new vessel formation on disc in chronic simple glaucoma. Disc shows shallow cupping and a venous anastomosis between the central vein and a tributary vein.

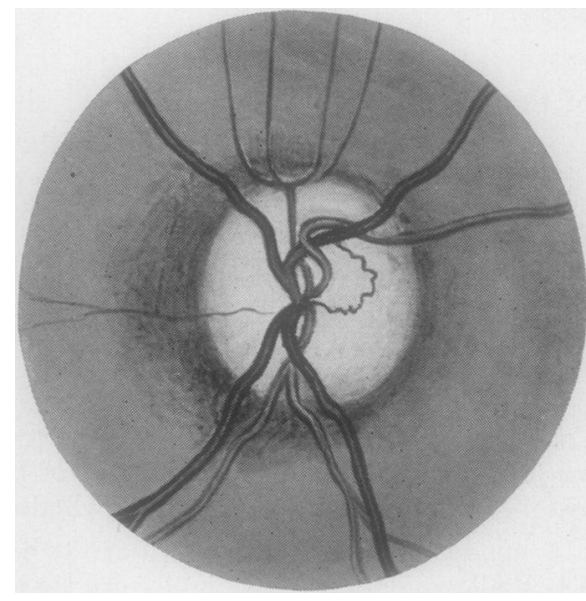

FIG. 1.-Case 1, right eye, showing new vessel formation on disc in chronic simple glaucoma. Disc shows shallow cupping and a venous anastomosis between the central vein and a branch vein.

Case 2, male, aged 61, came to the Eye Infirmary, Medical College, Calcutta on November 6, 1953, complaining of failing vision during the last 6 months.

Examination.-Right, visual acuity finger movement only. Left, visual acuity 6/24. In both eyes the anterior chamber was shallow and the ocular tension $49 \mathrm{~mm}$. $\mathrm{Hg}$ (Schiötz). Both discs showed cupping with optic atrophy and new vessel formations in anastomotic loops (Fig. 2). In the right eye a communication was found between a small vein arising from the trunk of the central vein and a twig arising from a main branch vein. In the left eye there were two venous communications, one between two nasal branch veins and the other between a temporal branch vein and a twig from the central vein. The neovascularization was limited to the disc, the rest of the fundus being normal.

Blood and urine examinations showed nothing abnormal, the Wassermann reaction was negative, and the blood pressure $145 / 85$.

Therapy.-On November 7, 1953, the left eye was trephined. When the patient was last examined (January 21,1954$)$ there were no further changes in the vessel formations on the discs, and the rest of the fundi was normal. 


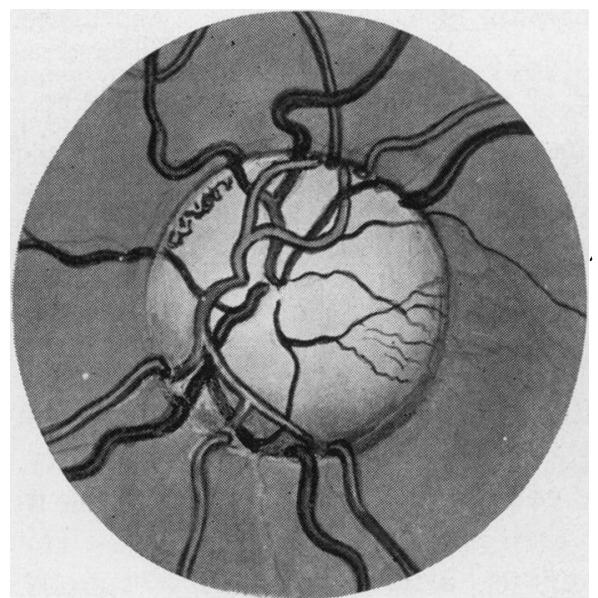

FIG. 2.-Case 2, left eye, showing new vessel formations on disc in chronic simple glaucoma. Disc shows deep cupping and two venous anastomoses, one between two branch veins and the other between a branch vein and a central vein.

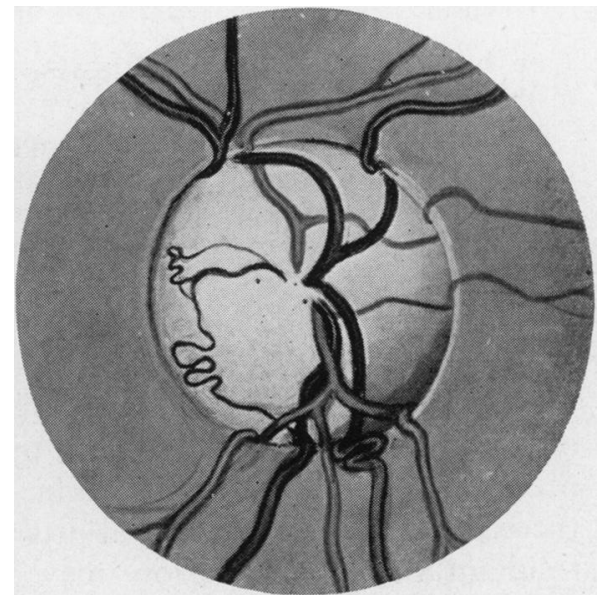

FIG. 2.-Case 2, right eye, showing new vessel formation on disc in chronic simple glaucoma. Disc shows deep cupping and a venous anastomosis between the central vein and a main branch vein.

Case 3, male, aged 54, came to the Eye Infirmary on November 12, 1953, with a history of gradual loss of vision.

Examination.-Right, visual acuity 3/60. Left, visual acuity finger movements only. In both eyes the cornea was clear, and the anterior chamber shallow. Ocular tension of the right eye was $30 \mathrm{~mm}$. Hg (Schiötz), and of the left eye $35 \mathrm{~mm}$. $\mathrm{Hg}$ (Schiötz). The right

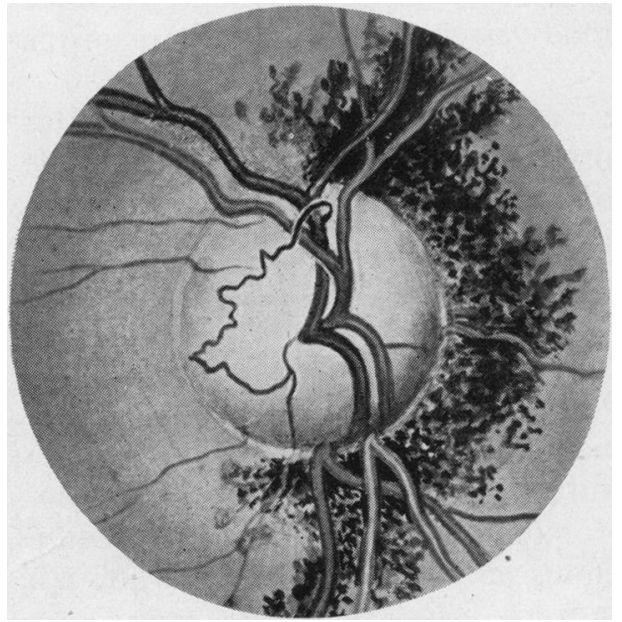

FIG. 3.-Case 3, right eye, showing new vessel formation on disc in chronic simple glaucoma. Disc shows deep cupping and a venous anastomosis between the central vein and a main tributary vein. The well-marked peripapillary pigmentation is congenital. disc showed glaucomatous cupping with optic atrophy and very marked congenital peripapillary pigmentation. On the temporal half of the disc, there was an anastomotic venous loop with communication between a twig from the trunk of the central vein and a twig from the main branch vein (Fig. 3). There was no neovascularization of any other part of the retina and the rest of the fundus was normal. The left disc showed marked glaucomatous cupping with optic atrophy, but no new vessel formation on either the disc or the retina. There was slight congenital pigmentation on the nasal side of the disc.

Blood and urine examinations showed nothing abnormal. The Wassermann reaction was negative, and the blood pressure $155 / 90$.

Therapy.-On November 18, 1953, iridencleisis was performed on the right eye. 
When the patient was last examined on January 16, 1954, both fundi were unchanged.

Case 4, male, aged 50, attended on October 5, 1953, with the history of loss of vision in the left eye.

Examination.-Right, visual acuity 6/18, fundus normal. Left, visual acuity finger movements only, anterior chamber shallow, tension full on digital examination; disc showed marked cupping with optic atrophy and neovascularization in the form of an anastomotic venous loop. The rest of the fundus was normal. No further investigations were made as the patient did not return to the clinic.

\section{Discussion}

New blood vessels grow on the disc and the retina either as a manifestation of congenital vascular defect or through ocular diseases of inflammatory, neoplastic, or haemorrhagic origin. The commonest cause is obstruction to the central vein or the central artery or their tributaries or branches. The resultant neovascularization may be venous, arterial, or arterio-venous, according to the nature of the aetiological factor.

The mechanism of their formation in the above conditions is not difficult to understand. It is also easy to understand how the new blood vessels grow on the retina in the secondary glaucoma following thrombosis of the central vein, but it is difficult to explain why new blood vessels form on the disc in chronic simple glaucoma.

In the four cases described above, the new vessels on the disc were veins. The first patient had chronic simple glaucoma in both eyes, and before the appearance of new blood vessels there was extensive retinal haemorrhage in the right eye, the cause of which was unknown. The neovascular formation on the right disc might thus be secondary to the retinal haemorrhage, but there was no apparent reason for the new blood vessels in the left disc, or in the other three cases.

The mechanism at work in all these cases may perhaps be explained as follows: In every case the anastomotic process has one definite pattern. The communicating loop is a vein and the communication is between two veinseither the trunk of the central vein and a tributary vein or between two tributary veins. The site of origin of the communicating twig from the branch vein is always beyond the crossing of the vein by an artery. In glaucoma when there is rise in ocular tension, the pressure effect is transmitted at the arteriovenous crossing on the disc where the already compressed vein is further constricted so that there is partial obstruction to the venous flow. When the obstruction is complete, the fundus picture is that of thrombosis of a tributary vein. But when it is partial and probably intermittent, the obstruction to the vein leads to the formation of a venous shunt which is Nature's attempt to get rid of the block.

As a result of the venous shunt, the blood in the obstructed vein can flow back and empty into the central vein via the communicating loop. The process of obstruction will be aggravated if co-existent arteriosclerotic change is already present in the vessel wall. All these four patients were over 50 
years old, so that some degree of senile arteriosclerosis could be expected, though no serious change was detected ophthalmoscopically. None had any sign of inflammation in the fundus, and the lesions were not of a neoplastic nature. Except the right eye of Case 1, none had any history of haemorrhage The theory of partial and intermittent venous obstruction due to raised ocular tension is the only likely explanation for appearance of a new venous shunt on the disc.

\section{Summary}

Four cases of chronic simple glaucoma are described in which new anastomotic veins were seen on the disc. In one eye of Case 1 the neovascular formation probably had a haemorrhagic basis, but for the rest no aetiological explanation apart from the raised ocular tension due to glaucoma presented itself. The possible mechanism of the neovascularization of the disc through the effect of raised tension is described.

\section{REFERENCES}

AXENFELD, T. (1911). Z. Augenheilk., 25, 362.

BLOCH, H. (1906). Klin. Mbl. Augenheilk., 44 (2), 413.

DUKE-ELDER, S. (1940). "Text-book- of Ophthalmology", vol. 3, pp. 2612-22. Kimpton, London.

Fuchs, A. (1951). "Diseases of the Fundus Oculi with Atlas", trans. E. Pressburger, p. 42. Lewis, London.

Hormuth (1903). Klin. Mbl. Augenheilk., 41, Beilageheft, p. 255.

KraUPA, E. (1915). Arch. Augenheilk., 78, 182.

Von Graefe, A. (1854). v. Graefes Arch. Ophthal., 1, pt. 1, 362. 